\title{
Synthesis of photoluminescent silicon nanoparticles by simple mechanical- milling for optoelectronics
}

\author{
Abhay Bhisikar ${ }^{1,2 *}$, Rajeev Gupta ${ }^{2}$ and Keshawa Shahi ${ }^{2}$ \\ ${ }^{1}$ Pulsed High Power Microwave Division, Raja Ramanna Centre for Advanced Technology \\ (RRCAT), Indore-452013, Madhya Pradesh, India \\ ${ }^{2}$ Materials Science Programme, Indian Institute of Technology (IIT), Kanpur-208016, Utter Pradesh, \\ India \\ *Email: bhisikar.abhay@gmail.com
}

It is possible to make light emissive silicon ( $\mathrm{Si})$ nanoparticles using ball-milling technique. In the present work it is reported that simply mechanically-milled $\mathrm{Si}$ particles can show photoluminescence (PL) at room temperature when their size reduces to less than $5 \mathrm{~nm}$. The blue-shift in their luminescence spectra is also observed. These facts can make them very good potential candidate for their application in optoelectronic devices.

We observed room temperature PL in visible spectrum (table 1) from the milled Si particles and determined their size by the model given by G. C. John et al. [1]. These particles gave PL in visible region when their dimension was found to be in $\mathrm{nm}$ range $(<5 \mathrm{~nm})$. The results obtained are consistent with those obtained by S. Yerci et al. [2], however it is the first time when such PL was observed from $\mathrm{Si}$ nanoparticles synthesised in simple and economical way. The blue shifts (the compaction in wavelength i.e. shifting of wavelength towards the blue line $475 \mathrm{~nm}$ ) from these particles are observed.

Table 1: Comparative study of PL spectra of ballmilled Si particles

\begin{tabular}{|l|l|l|l|l|l|}
\hline $\begin{array}{l}\text { Milli } \\
\text { ng } \\
\text { time } \\
(\mathbf{h})\end{array}$ & $\begin{array}{l}\text { Millin } \\
\text { g } \\
\text { speed } \\
(\mathbf{r p m})\end{array}$ & $\begin{array}{l}\text { Materia } \\
\text { I system } \\
\text { of ball } \\
\text { and } \\
\text { bowl }\end{array}$ & $\begin{array}{l}\text { Number } \\
\text { of } \\
\text { promine } \\
\text { nt peaks } \\
\text { in PL } \\
\text { spectra }\end{array}$ & $\begin{array}{l}\text { PL peak } \\
\text { position } \\
(\mathbf{n m})\end{array}$ & $\begin{array}{l}\text { Particle } \\
\text { size } \\
\text { calculated } \\
\text { using } \\
\text { model } \\
\text { given in [1] } \\
\text { (nm) }\end{array}$ \\
\hline 201 & 400 & Agate & 1 & 698 & 2.50 \\
\hline 114 & 500 & Agate & 2 & 693 & 2.48 \\
\hline 126 & 500 & Agate & 2 & 690 & 1.92 \\
\hline 252 & 500 & Agate & 2 & 699 & 2.47 \\
\hline 63 & 400 & WC & 1 & 693 & 2.92 \\
\hline 101 & 400 & WC & 2 & 683 & 2.46 \\
\hline 194 & 400 & WC & 3 & 566 & 2.02 \\
\hline & & & & 694 & 2.48 \\
\hline
\end{tabular}

The PL spectra and the scanning electron microscopy (SEM) for a typical case of $201 \mathrm{~h}$ and 400 revolution per minute (rpm) ballmilled Si sample in ethanol medium with ball and bowl of agate are shown in Figure 1. Such easy ball-milling produces clustered $\mathrm{Si}$ nanoparticles, which may be caused by mechanical energy generated during the milling process. These clusters are indeed observed by the SEM in extended prolate and spheroid forms.

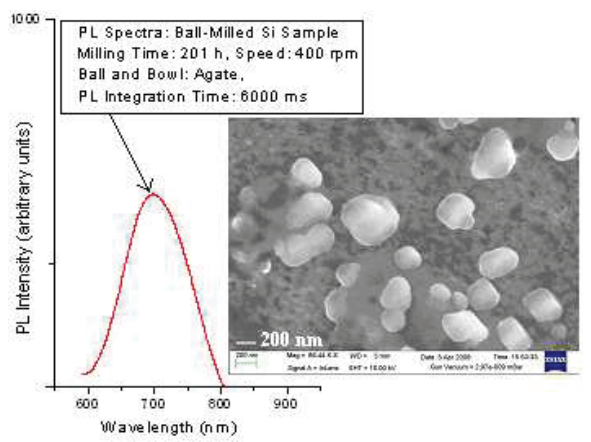

Figure 1: PL spectra and SEM image of $201 \mathrm{~h}, 400$ rpm ball-milled $\mathrm{Si}$ sample with ball and bowl of agate

The milled Si particles smaller than $5 \mathrm{~nm}$ can exhibit PL at room temperature and this can make them very significant for optoelectronic device applications, such as, in light emitting diodes (LEDs) and lasers.

Acknowledgements: The results presented in this paper are the part of Abhay Bhisikar's Master of Technology (MTech) thesis work submitted to Materials Science Programme, IIT, Kanpur in partial fulfilment of the requirements for the degree.

\section{References}

1. G. C. John, V. A. Singh, Phys. Rev. B, vol. 50, no. 8, pp. 5329-5334, Aug 1994

2. S. Yerci, U. Serincan, I. Dogan, S. Tokay, M. Genisel, A. Aydinli, R. Turan, J. Appl. Phys., 100, 074301-5, 2006 